The work described here is preliminary. The mosses need to be classified according to species and age. In addition, the sampling programme should be expanded to include downwind sampling from densely populated and industrial areas. Contour maps of mercury levels can be developed from these types of data. It would be desirable to know more about moss growth in highly industrialized areas. Methods of encouraging the growth of the more hardy varieties need to be developed.

JBF Scientific Corporation,

2 Ray Avenue,

Burlington, Massachusetts

Received September 23, 1971.

1 Jaakkola, T., Miettinen, J., and Takahoshi, H., Proceedings of World Health Organization Meeting, Geneva, 1971 (in the press).

${ }^{2}$ Ruhling, A., and Tyler, G., Bot. Notiser, 122, 218 (1969).

3 Rühling, A., and Tyler, G., Oikos, 21, 92 (1970).

4 Williston, S. H., J. Geophys. Res., 73, 22 (1968).

5 Boengen, J. G., Shacklette, H. T., and Turner, R. L., US Geological Survey Circular, 644 (1971).

- Conard, H. S., The Mosses and Liverworts (Brown, Dubuque, 1956).

\section{Possible Biochemical Model for Phenylketonuria}

SINCE the demonstration of the primary enzymatic defect in phenylketonuria (PKU) several models have been suggested for this metabolic disorder. No hypothesis, however, has unified the biochemical and clinical characteristics ${ }^{2}$.

Weber et $a l^{3}{ }^{3}$ demonstrated an effect of phenylalanine and phenylpyruvic acid (PPA), the two major metabolites found in PKU, on the metabolism of glucose. They observed inhibition by either phenylalanine or PPA of three specific enzymes of glycolysis: hexokinase, pyruvate kinase and 6-phosphogluconate dehydrogenase. On the basis of these data, Weber suggests that phenylalanine and PPA interfere with the biosynthesis of strategic macromolecules in the differentiating brain. He supports this hypothesis by showing that the extent of decreases in the incorporation of radioactively labelled glucose into lipid, RNA and DNA depends on the dose of phenylalanine or PPA. A major shortcoming of the various models is the lack of an adequate explanation of the aetiology of the deficiency in myelin deposition seen in patients. In an attempt to define the causes of the clinical symptoms of PKU, and this deficiency in particular, we have sought preliminary evidence that PPA is the key metabolic factor in PKU.

Homogenates of whole fresh rat brain and liver were prepared in cold $0.25 \mathrm{M}$ sucrose $(1 \mathrm{~g} / 10 \mathrm{ml}$.) and incubated as described previously ${ }^{4}$ to measure the production of ${ }^{14} \mathrm{CO}_{2}$ from ${ }^{14} \mathrm{C}-1$-pyruvate. In the first study, both rat brain and rat liver homogenates were used to determine the levels of inhibition by the various metabolites of phenylalanine present in patients with untreated PKU (Table 1).

Of the five metabolites tested, none were significantly inhibitory in the liver, but phenylpyruvic acid (PPA) inhibited

Table 1 Relative Inhibition of Pyruvate Decarboxylation in Rat Liver and Brain Homogenates by Various Metabolites of Phenylalanine

\begin{tabular}{|c|c|c|}
\hline \multirow[b]{2}{*}{ Metabolite added * } & \multicolumn{2}{|c|}{ Relative activity } \\
\hline & Brain & Liver \\
\hline None ${ }^{+}$ & $100 \%$ & $100 \%$ \\
\hline$\beta$-Phenylpyruvic acid & 53 & 92 \\
\hline DL- $\beta$-Phenyllactic acid & 98 & 94 \\
\hline DL-3-Indolelactic acid & 80 & 84 \\
\hline Indole-3-Acetic acid & 84 & 82 \\
\hline 3-Indolepyruvic acid & 106 & 169 \\
\hline
\end{tabular}

* All metabolites at $1 \times 10^{-2} \mathrm{M}$.

$\dagger$ Homogenates were incubated with $1 \times 10^{-3} \mathrm{M}$ pyruvate for 15 min at $37^{\circ} \mathrm{C}$.

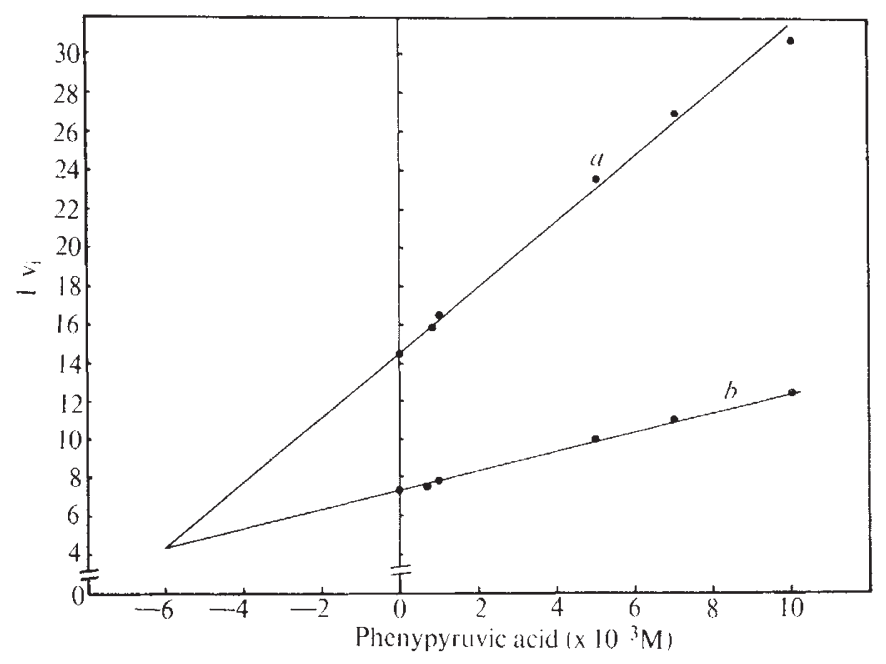

Fig. 1 Effects of PPA on pyruvate decarboxylation. a, Pyruvate $5 \times 10^{-4} \mathrm{M} ; b$, pyruvate $1 \times 10^{-3} \mathrm{M}$.

pyruvate metabolism in the brain by $50 \%$. We therefore thought it important to determine the type of inhibition exerted by PPA. We measured the effect of various amounts of PPA at two concentrations of pyruvate and plotted the data by the method described by Dixon ${ }^{5}$ (Fig. 1). Clearly PPA is a competitive inhibitor of pyruvate decarboxylation, with a $\mathrm{K}_{1}$ of approximately $6 \times 10^{-3} \mathrm{M}$ in brain homogenate.

These results indicate that, of the metabolites of phenylalanine which accumulate in significant amounts in PKU, only PPA specifically inhibits pyruvate decarboxylation and then only in the brain.

As pyruvate metabolism is central to the energy cycle in adult and developing brain, it is significant that PPA inhibits this important system. We suggest that in PKU an "induced" metabolic block (inhibition) at the site of pyruvate decarboxylation depresses the amount of acetyl-CoA derived from carbohydrate metabolism for energy production through the tricarboxylic acid cycle. Furthermore, a depression in pyruvate metabolism would decrease the amount of acetyl-CoA available for the synthesis of fatty acid and cholesterol which are primary precursors of myelin. This specific site of inhibition coupled with the effects on glycolysis noted by Weber et al. ${ }^{3}$ would starve the brain tissue of energy. Such a condition could be responsible for the depression in synthesis of myelin and myelin precursors, explaining the reduced myelin deposition found concomitant with the mental retardation in PKU. The observation that these phenylalanine metabolites do not inhibit pyruvate decarboxylation in the liver to the same degree as in the brain suggests that other body functions are relatively normal while the brain is starved of energy. Our observations support the hypothesis that PPA inhibition of pyruvate metabolism plays an important role in the aetiology of the mental retardation found in PKU.

We thank the National Institutes of Health and the Florida Heart Association for grants.

\section{JOE A. BOWDEN*}

C. L. MCARThur III

Department of Biochemistry,

University of Florida, College of Medicine, Gainesville, Florida 32601

Received July 27, 1971.

* Present address: Louisiana State University, Department of Biochemistry, Baton Rouge, Louisiana 70803.

1 Jervis, G. A., Proc. Soc. Exp. Biol., 82, 514 (1953).

2 Menkes, J. H., Pediatrics, 39, 297 (1967).

3 Weber, G., Glazer, R. L., and Ross, R. A., Adv. Enzyme Regulation, 8, 13 (1970).

4 Bowden, J. A., McArthur III, C. L., and Fried, M., Biochem. Med., 5, 101 (1971).

5 Dixon, M., Biochem. J., 55, 170 (1953). 